\title{
Problems and Countermeasures for the Knowledge- enabled Human Resource Cultivated in Henan under the View of Building Central Plains Economic Region
}

\author{
Yehong He \\ Henan Institute of Education \\ Zhengzhou, China 450046
}

\begin{abstract}
Advancing with the release of the 13th five-year plan outline and the access to the strategic implementation stage of the Central Plains Economic Region, the economic development in Henan province, especially Zhengzhou is facing god-given development opportunities that are never seen before. Facing such opportunities and development, talents and technologies, acting as essential drives and accelerators, have to face problems increased day by day, especially to cultivate the knowledge-enabled human resource has heavier tasks with higher requirements and higher responsibilities to be taken, which has became a significant factor influencing the achievement of economic development goals. Based on the study upon economic police guide, geographical advantages, fund support and so on, this paper collects and processes relevant survey data and introduces briefly the background of the Central Plains Economic Region, deeply analyzes the status quo of human resources especially the knowledge-enabled human resource cultivation and development in Henan province which acts as the main body of the Central Plains Economic Region, and this paper gives a special study on all kinds of human resources which play key roles in the building of the Central Plains Economic Region. Meanwhile, this paper studies and borrows the regional economic constructions being done in developed and developing countries and regions at home and abroad, and finds the deficiency of human resource development in the Central Plains Economic Region and raises corresponding solutions and countermeasures.
\end{abstract}

Keywords-knowledge-enabled human resource cultivated; Central Plains Economic Region; corresponding solutions

\section{MeAning And VAlue Formation OF KNOWLEDGE- ENABLED HUMAN RESOURCE}

The knowledge-enabled human resource refers to intellectual workers who are mainly engaged in the production, creation, distribution and application of knowledge and create welfare successfully for the society during the course of social production. As one part of human resources, the knowledge-enabled human resource owns important value that cannot be replaced, which, on the one hand, is embodied in the totality of materials and labor service consumed for the production, development, maintenance and reproduction of the knowledge-enabled human resource. On the other hand, since the knowledgeenabled human resource differs from general material assets, which owns higher subjective consciousness and creativity, accordingly its value should fully embody the potential for future service of knowledge-enabled work. Seen from production and application, the value of knowledge-enabled human resource consists of cost value and newly added value, of which, the cost value refers to the cost to form the knowledge-enabled work capability made in advance by the knowledge-enabled human resource during the course of obtaining the knowledge and skills necessary for the knowledge-enable work, namely the full cost paid by the knowledge-enabled human resource to obtain knowledge and skills owned, which includes education fees, special training costs and opportunity cost and the costs to produce experience knowledge in working. The newly added value refers to the value or benefits obtained by an enterprise via the application of the knowledge-enabled human resource, namely the service value the knowledge-enabled human resource provides with the knowledge and skills after entering an enterprise.

\section{ANALYSIS ON THE STATUS QUO OF HUMAN} RESOURCES ESPECIALLY THE KNOWLEDGE-ENABLED HuMAN RESOURCE TO BUILD THE CENTRAL PLAINS ECONOMIC REGION

\section{A. High Quantity of Human Resources but with Illogical} Human Resource Structure and Lack in the KnowledgeEnabled Human Resource

Data show that the quantity of human resources in Henan totaled 71.66 million persons in 2011, of whom, the population aged 16 or more participating in the economic activity reached 59.8728 million persons, the population engaged reached 59.4878 million persons, which occupies $99.4 \%$ of the population participating in the economic activity, it takes up $83.1 \%$ of the total human resources in Henan. The quantity of population engaged in the primary industry reached 27.6486 million persons, occupying $46.5 \%$ 
of the total people engaged; The quantity of population engaged in the second industry reached 16.7472 million persons, occupying $28.2 \%$ of the total people engaged; The quantity of population engaged in the third industry reached 59.8728 million persons, occupying $25.3 \%$ of the total people engaged; however, the quantity of knowledgeenabled human resource or talents totaled 6.48 million persons, occupying $10.1 \%$ of the people engaged, and $9.0 \%$ of the total human resources. Of whom, the talents in the Party and political work reached 350000 persons, the professional technicians reached 2.76 million persons, the enterprise managers reached 1.1 million persons, and the highly skilled workers reached 1.03 million persons, and the workers for rural work reached 1.24 million persons. The talents with high level technical titles in the professional technical workers reached 160000 persons, and the workers with medium level titles reached 600000 persons, which occupies $5.8 \%$ and $21.7 \%$ of the professional technicians respectively. The medium and high level technicians remain a lower proportion. Therefore, seen from the totality, for the economic development goal requirement and the total human resources, the knowledge-enabled human resource, compared to the human resources in all industries, is in a serious lack.

\section{B. Outstanding Problems in the Acceptance, Fostering, Development Atmosphere and Environment, Lack of Proper Investment in the Human Capital}

The acceptance, training and excitation mechanism for talents are imperfect in Henan, the human resource market mechanism is imperfect, the knowledge-enabled human resource market remains in a lower degree for distribution, systems of domicile, human resources and so on have seriously blocked the rational flow of talents. The knowledge-enabled enterprises accepting knowledge-enabled human resource know little to make use of quality talents, especially in some regions with poor economy in Henan, influenced by traditional employment modes, there are still leaders who seek for employing talents but give little attentions to the exertion of talents; high attentions are paid to the quantity of talents with higher education, but little attentions are paid to the talents' skill improvement and utilization, and the potentials of knowledge-enabled human resource fail to be converted into economic benefits, and the knowledge-enabled human resource has no environment created for development and exertion. Meanwhile, the educational costs in Henan is seriously lower than the per capita educational cost across the country, and serious lack of educational costs are invested to professional educational and continued education, which is far to reach the goal given in the talent development outline.

\section{Irrational Industrial Distribution and the Status Quo of Enterprises Accepting the Knowledge-Enabled Human Resource Accelerate the Outflow of Knowledge-Enabled Human Resource}

Henan is a large province of rural production, the quantity of population engaged in the primary industry reached 27.6486 million persons, occupying $46.5 \%$ of the total people engaged; The quantity of population engaged in the second industry reached 16.7472 million persons, occupying $28.2 \%$ of the total people engaged; The quantity of population engaged in the third industry reached 59.8728 million persons, occupying $25.3 \%$ of the total people engaged; in the same term, the distribution structure ratios of the people engaged out of the national human resources in the three industries are $38.1 \%, 27.8 \%$ and $34.1 \%$ respectively. The third industry develops poorly and the primary industry occupies most of the laborers. Meanwhile, due to the imbalanced economic development, a great number of knowledge-enabled human resources flow into costal cities and other developed regions, which have caused serious outflow of talents and the lack of quality knowledgeenabled human resource in Henan.

\section{MaIN PROBlems EXISTING FOR ACCEPTANCE, FOSTERING AND EXCITATION OF KNOWLEDGE-ENABLED Human Resource for BuILding THE CENTRAL Plains ECONOMIC REGION}

A. Poor Knowledge to Characteristics of KnowledgeEnabled Human Resource Caset that the Setting of Acceptance, Fostering and Excitation Modes are Deeply Influenced by Traditional Modes

The knowledge-enabled employees have diverse characteristics which we should make deep analysis on the special group and work, and adequate knowledge shall be based on for scientific management. Yet, in most cases, the acceptance, fostering and excitation modes in Henan are still kept in the partial improvement of old modes, which fail to fully stir the enthusiasm and make rational excitation. In my opinion, main characteristics of knowledge-enabled human resource are mainly embodied in the following: Seeking independence, full of innovative spirit. (2) Individuation of work flow for knowledge-enabled employees. The work of knowledge-enabled employees is a complex thought process in the brain, which is out of the restriction of time and space, having no given flow or procedures, yet with higher independence and autonomy. (3) Unique values. According to the Maslow's Hierarchy of Needs, the knowledge-enabled employees belong to higher hierarchy, who are of self management, innovation and expecting to achieve the value of their own. The given work goals will make them focus on the achievement of values of their own and expect the acknowledgement by the society. (4) Strong flow inclination and team cooperation spirit. The knowledge replaces the capital in the knowledge economy and becomes the first resource. The employment relationship turns from capital employing knowledge to knowledge employing capital. The change of employment relationship determines that the employment period shall depend on the knowledge-enabled employees, and the talent flow becomes popular in the knowledge-enabled enterprises. And the union and cooperation and mutual discussion become the keys for success of an enterprise. (5) Labor course hard to monitor and labor achievement hard to measure. The work of knowledge-enabled employees is thinking activity via the brain, and the labor course is invisible, and the work has no given flow or procedures and there are no fixed labor rules, 
therefore, it's no use to monitor the labor course, in addition, it is impossible to do as well. Besides, the innovative achievements obtained in this hierarchy are mostly based on team wisdom and hard work, which is hard to divide. The work achievement of knowledge-enabled employees cannot be measured easily just like the achievements of general laborers, all of which make it difficult to measure the individual achievements of knowledge-enabled employees.

\section{B. Lack of Scientific and Rational Strategy of Knowledge- Enabled Human Resource and Poor Human Resource Management}

At present, little attentions are paid to the importance of knowledge-enabled human capital in Henan, and there are no human resource development strategies supporting the development layout and strategy for enterprises and institutions. In case cases, attentions are paid to how to identify and select talents yet there are no long term strategies for complete talent fostering and layout, which case that the enterprises have no strength for growth and are in the lack of advanced management and technical backbones. II. Lack of rational knowledge-enabled employment mechanism and hard to absorb quality talents; Due to the background of state-owned enterprises and traditional culture, it is difficult for many enterprises to absorb high quality talents. Especially many nongovernmental enterprises still employ relatives, and the family and blood relationships are based to determine the employees' position in the enterprises and the unreasonable promotion and examination systems make it difficult for the knowledge-enabled human resource to exist in the enterprises. III. Lack of long term and efficient knowledgeenabled talent salary excitation mechanism. With the social progress and improvement of living conditions, the single salary system is hard to meet the demand of core employees, and many enterprises give a high pay to excite employees that yet fail to stir the enthusiasm of employees, instead, the knowledge-enabled human resource feel dissatisfied and the work efficiency is lowered. Main reasons are unfair and irrational excitation measures. IV. Lack of human-orientated employment concept; With the generally increased education level of knowledge-enabled employees, to regard talents, trust talents and develop talents become more and more important in the enterprise's human resource management, and the negligence to meet the work achievement sense of knowledge-enabled human resource cases the talent's outflow.

\section{Multi-Dimensions, Multi-Factors And DIVERSITY OF MANAGEMENT ACHIEVEMENTS OF KNOWLEDGE-ENABLED HuMAN RESOURCE CAUSE THE LACK OF INNOVATION IN THE SPECIAL GROUP MANAGEMENT}

The obvious characteristics of knowledge-enabled employees make the human resource management of knowledge-enabled enterprises has new characteristics, yet our human resource management is still in the stage of traditional administrative personnel management, which is mainly embodied in the following: 1) Closed management mode. The human resource management fails to adapt to the development tendency of globalization, knowledge and informatization in the knowledge economic time, hard to free from traditional closed and rigescent personnel management modes, and unable to borrow new concepts, knowledge and methods from other subjects and fields to expand the thought and improve the management modes. 2) Non-dynamic management course. People's thought and consciousness change continuously only can dynamic management modes explored meet the changes and develop with the time. 3) Unscientific management mode. Human resource managers still keep traditional personnel management modes, failing to conduct work analysis and study with scientific attitudes, knowledge and methods of system engineering, maths and statistics. 4) Un-conspicuous management humanization tendency. Enterprises neglect to exert the independence and innovative spirit of employees, failing to enable employees to control and develop themselves via rational authorization. 5) Negligence of management innovation. In case of the management innovation, on the one hand, the human resource department shall keep continuous self innovation; on the other hand, it shall continuously develop and release new service products and promote the enterprises' overall innovation.

\section{THOUGHT AND COUNTERMEASURES TO PROMOTE STANDARDIZED AND EFFICIENT KNOWLEDGE-ENABLED HUMAN RESOURCE FOSTERING}

Innovation of knowledge-enabled human resource management modes for enterprises. When managing knowledge-enabled employees, the enterprises should focus on the management modes and measures, which are detailed as follows:

\section{A. Form the Guide Thought of "Based on the Demand of Knowledge-Enabled Human Resource”,}

The enterprise shall form the guide thought of "knowledge-enabled human resource is important resource and knowledge-enabled capital is important capital", which shall be carried out in the enterprise's management and service. First of all, starting from the "decision makers". The human resource management innovation is involved in the enterprise's organization structure and personnel arrangement, besides, a great number of personnel and financial resources shall be invested, if there are no strong support from the organization leaders, the innovation work will fall by the wayside. Second, starting from medium leaders of departments. The human resource management is involved in the enterprise's departments and employees, it is not only the task of human resource department but also the task of each department, and whether the departments' leaders regard it or not will directly the efficiency of the human resource management. The human resource management departments shall change the roles, it shall be changed from traditional personnel control to a service unit to provide assistance for the self development of employees, and provide individualized service to diverse knowledgeenabled key employees within the organization framework. 


\section{B. Innovation of Salary Excitation Mechanism}

The salary is a scale to measure the relations between enterprise and employees, whether the employees are satisfied with the enterprise or not can be a reflection from they are satisfied with the salary or not. As for the knowledge-enabled employees, it shall not just take the salary as an economic exchange relation with the economic views as organizer, the salary should be regarded from the psychology, starting from the individual angle, it shall emphasize how the individual evaluate the salary and how the salary influence his behaviors and attitudes, which embody the psychological contract between employees and organizer. The knowledge-enabled employees hold certain motive to enter the enterprise which is expected to satisfy the employees in material and spirit; and the enterprise, via the human resource management, shall make full of the human resource to achieve the enterprise's goals. The social relation between employees and enterprise makes it impossible to define completely the responsibilities of two sides in the written employment contract, yet, in the heart of each knowledge-enabled employees, they should have clear knowledge to what to do, how to do and what salary to get in the enterprise. Seen from the core, the psychological contract is a psychological tie to connect employees and the enterprise, which will influence the employees' commitments to the enterprise, work achievement, flow rate and finally the enterprise achievements. As for the continuous innovation excitation mechanism, the enterprise shall provide efficient growth mechanism and make the enterprise get long term development potentials via absorbing and exciting employees, which is a win-win strategy.

\section{Flexible Management}

High quality personnel structure determines that the flexible management shall be the optimal method for the human resource management in the knowledge-enabled enterprises. Generally speaking, whether the management environment is strict or loose is often related to the high or lower quality of employee teams, namely loose management is applicable for higher wisdom and high educational background employee teams, and the relatively strict management modes is much applicable for the employee team with lower educational background. The knowledgeenabled enterprise is a talent intensive enterprise, and the enterprise culture-based behavior guided flexible management mode shall be the optimal method for the human management in such enterprise. However, the loose systems shall not exclude competition, and in reverse the competition mechanism shall be the main factor in the knowledge-enabled enterprise culture.

On the one hand, the loose working environment will provide a stage for each employee to exert their ability and show their brilliance; on the other hand, the competition can bring drive and restriction to the employees.

\section{To Create Fine Working Environment}

The working environment includes physical environment and cultural environment, the physical environment refers to working and living conditions the enterprise provides to employees; the cultural environment refers to work atmosphere, enterprise and cooperative teams, etc. The enterprise shall not only provide employees with a comfortable physical environment and work hard to create a favorable cultural environment, which will be taken as measures to introduce and keep talents. In the knowledge economy time, the knowledge-enabled employees pay more attention to the cultural environment, and the enterprises with outstanding leaders who employ talents according to their abilities, harmonious and progressive enterprise culture, cooperative and efficient team as well as elastic work systems become much popular by the knowledge-enabled employees, and such environment can much stir the employees' work desire and work passion.

\section{E. To Establish Fine Training Mechanism and Professional Layout Mechanism}

To establish a systematic human resource development training mechanism according to characteristics of knowledge-enabled human resource, first of all, the enterprise should change concepts and take the development training as an investment, which shall be the most important investment but not consumption. Second, to make the human resource layout. The human resource layout refers that the enterprise predicts the human resource so as to exercise the development strategy and achieve its goals and make systematic arrangement in advance to meet such demand. Third, to make scientific and systematic development and training plans according to the human resource layout. Fourth, to widen the talent source channels. On the one hand, develop new human resource via digging the employees' potentials; on the other hand, make full use of external human resources via methods such as lease, cooperation and short term visit, etc. Of course, to frame an excitation system for the knowledge-enabled employee training, in order to assure normal training and increase the training efficiency, it is necessary to provide the knowledge-enabled employees with training excitation. The most efficient method is to connect the training with the knowledge-enabled employees' career management.

For the knowledge-enabled employees, the fine vocational career is also a focus they pay more attention to, therefore, except the favorable training mechanism, the employees shall be supported to create favorable vocational career layout, and the employees' vocational development shall be guided. Help employees establish vocational development layouts, and design an applicable individual development way, and make the employees know their prospects, clear goals in the enterprise, and the support from the enterprise. It connects the employees' individual struggle with the enterprise's development, based on which, the employees struggle for the goals of their own and contribute a lot to the enterprise's development.

\section{CONCLUSION}

In conclusion, the human resource especially the knowledge-enabled human resource has become a core strategic resource for the social development and economic 
construction, which will provide intellectual support and strategic bracing to build the Central Plains Economic Region, the key point for the full construction of the Central Plains Economic Region depends on whether the world eyesight and strategic thought are adopted to plan the talent gathering land and develop the thought, create the mechanism and soil for fostering the knowledge-enabled human resource, create an environment to keep and employ the knowledge-enabled human resource to the maximum and provide powerful intelligence support and talent guarantee for building the Central Plains Economic Region. Seen from whether the macroscopical hierarchy or the organizational microcosmic hierarchy, it is necessary to build a long efficient mechanism to increase the development efficiency of human resource and rapid growth of excellent talents, and favorable undertaking atmosphere to exert the unique advantages of knowledge-enabled human resource so as to promote the construction and development of the Central Plains Economic Region.

\section{REFERENCES}

[1] Outline for the Central Plains Economic Region Building Layout and Zhengzhou Airport Comprehensive Economic Experimental Zone Building Layout 2013-2025.

[2] Regarding and Creating Talents Fostering Highland to Provide Intellectual Support for Building the Central Plains Economic Region [J] Henan Education (M) 2011(01)

[3] Study on Solid Evidences of Excitation Factors for Knowledgeenabled Employees, Chen Jing'an, Scientific Technical Management 2005

[4] Fostering Excellent Talents to full Serve the Central Plains Economic Region Building [J] Wu Tingwei, Henan Education (M) 2011(01)

[5] Enterprise Culture Knowledge-enabled Human Resource Management [J], Zhang Meili, Operation and Management Jan, 2013

[6] Overall Study on the Excitation upon Knowledge-enabled Employees, Ju Qiong, Technical Market Economy Mar 2013. 